\title{
Article \\ Effect of Coronavirus-19 Restrictions in Male Handball Players: Physical Activity, Sedentary Behavior, and Satisfaction with Life
}

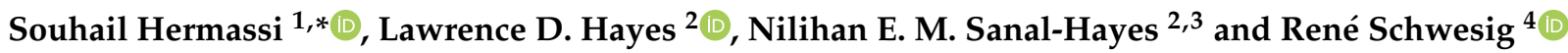 \\ 1 Physical Education Department, College of Education, Qatar University, Doha 2713, Qatar \\ 2 Institute of Clinical Exercise and Health Science, School of Health and Life Sciences, \\ University of the West of Scotland, Glasgow G72 0LH, UK; lawrence.hayes@uws.ac.uk (L.D.H.); \\ nilihan.sanal@outlook.com (N.E.M.S.-H.) \\ 3 Department of Psychology, Lancaster University, Lancaster LA1 4YF, UK \\ 4 Department of Orthopedic and Trauma Surgery, Martin-Luther-University Halle-Wittenberg, \\ Ernst-Grube-Str. 40, 06120 Halle, Germany; rene.schwesig@uk-halle.de \\ * Correspondence: shermassi@qu.edu.qa
}

check for updates

Citation: Hermassi, S.; Hayes, L.D.; Sanal-Hayes, N.E.M.; Schwesig, R. Effect of Coronavirus-19 Restrictions in Male Handball Players: Physical Activity, Sedentary Behavior, and Satisfaction with Life. Appl. Sci. 2021, 11, 11373. https://doi.org/10.3390/ app112311373

Academic Editors: Alessandro de Sire and Fernando Ribeiro

Received: 19 August 2021

Accepted: 26 November 2021

Published: 1 December 2021

Publisher's Note: MDPI stays neutral with regard to jurisdictional claims in published maps and institutional affiliations.

Copyright: (C) 2021 by the authors Licensee MDPI, Basel, Switzerland This article is an open access article distributed under the terms and conditions of the Creative Commons Attribution (CC BY) license (https:// creativecommons.org/licenses/by/ $4.0 /)$
Featured Application: This experiment aimed to test the effect home confinement had on sedentary behavior, physical activity (PA), and satisfaction with life (SL) in European and Middle Eastern and North African (MENA) handball players during the coronavirus (COVID)-19 pandemic. These results may be useful to develop recommendations for PA during protracted home confinement. Furthermore, these recommendations for home-based exercise interventions can improve participants' PA, which in turn would maintain the high energy of physical activity (HEPA) category in handball players during and after the COVID-19 pandemic.

Abstract: This experiment examined physical activity (PA), sitting time, and satisfaction with life (SL) in European (45\%) and Middle Eastern and North African (MENA; 55\%) handball players ( $\mathrm{n}=418$; age: $25.6 \pm 6.8$ years; body mass: $88.1 \pm 11.7 \mathrm{~kg}$; height: $1.83 \pm 0.08 \mathrm{~m}$ ) during the coronavirus (COVID)-19 pandemic. The International Physical Activity (IPAQ) and Satisfaction of Life (LS) Questionnaires were administered. All PA variables (vigorous, moderate, walking, total PA) were negatively influenced, but no interaction effects (IE; region $x$ time) were observed. Sitting time increased from 2.5 to $4.9 \mathrm{~h} \cdot$ weekday $^{-1}\left(\eta_{\mathrm{p}}{ }^{2}=0.80\right)$ and walking time decreased from 66.8 to $33.5 \mathrm{~min} \cdot \mathrm{day}^{-1}\left(\eta_{\mathrm{p}}{ }^{2}=0.83\right)$. Based on effect sizes $(\mathrm{d})$, pre- to during-confinement reductions were similar between regions (MENA: $d=3.29$; Europe: $d=3.41$; IE: $\eta_{\mathrm{p}}{ }^{2}=0.01$ ). The largest regional difference was in moderate PA (MENA: $d=1.88$; Europe: $d=2.99$; IE: $\eta_{p}{ }^{2}=0.09$ ). SL in the total sample reduced from $30.6 \pm 2.02$ to $13.9 \pm 2.20$ arbitrary units (AU). SL reduction was similar in both regions $\left(\mathrm{d}_{\text {MENA }}=8.44 ; \mathrm{d}_{\text {EUROPE }}=8.06\right.$; IE: $\left.\eta_{\mathrm{p}}{ }^{2}=0.01\right)$. To conclude, PA decreased during COVID-19 confinement, sitting time increased, and SL decreased irrespective of geographical region. These preliminary findings highlight risk of SL and physical inactivity during COVID-19 restrictions in 2021.

Keywords: coronavirus; COVID-19; team handball; playing level; confinement; physical activity

\section{Introduction}

The World Health Organization (WHO) WHO recommended several restrictions to in response to the coronavirus (COVID)-19 pandemic to control the spread of the virus. These restrictions entailed closure of schools and universities, no physical contact, banning of social gatherings and large events, and introducing quarantine, social distancing and confinement [1,2]. These restrictions, especially self-isolation and/or home confinement can influence mental and psychosocial health negatively, increase level of stress and negative emotions, and impair cognition [2]. If self-isolation and/or home confinement are enforced for a protracted time period, and physical activity (PA) is reduced during this time frame, 
immune function and physical capacity may be impaired as a result [3]. Moreover, reduced PA may also increase the disease progression and the severity of symptoms in humans after contracting the virus.

The COVID-19 outbreak has altered life patterns and the perception of infectious diseases among the general public. However, prolonged homestay could increase behaviors that lead to physical inactivity and increase stress, which in turn, could increase the risk of several chronic health conditions that adversely affect health-related quality of life [4]. For example, limiting daily activity has been found to impair health-related quality of life among severe acute respiratory syndrome (SARs) patients in Hong Kong [5]. During confinement, most individuals are living in an unprecedented situation of unknown duration, being exposed to anxiety, fear, depression, or sleep disruption [6,7].

The relationship between the coach and the athlete is one of the elements that receive greater attention from the sports community when referring to successes or failures of athletes [8-10] especially during the COVID 19 pandemic [11]. Coach-athlete relationship in a sports environment as a sense of belonging and noted the possible personal benefits of closeness with others [8]. The coach-athlete relationship, conceptualizing it as a repeating pattern of mutual care between athletes and coaches [8-10]. However, recently, Li et al. [11] showed that athletes of different age categories showed different changes in the coachathlete relationship after the lockdown, and the changes were not significantly related to the severity of the COVID-19 epidemic. In this study, it is confirmed that during the COVID 19, lockdown changes the way coaches and athletes communicate.

Reduced time spent in PA concomitantly increases symptoms of anxiety, depressive symptoms, and other chronic health diseases $[1,12,13]$. Taken together, these repercussions are a result of decreased PA in adults due to COVID-19 pandemic restrictions [14,15]. In terms of athletic populations, Dönmez et al. [16] reported $66 \%$ of professional soccer players exhibited post-traumatic stress disorder (PTSD) symptoms resultant of social isolation and home-quarantine. The psychological repercussions of COVID-19 may further interfere with training practices and recovery profiles in athletes [17], consequently inhibiting performance. PA frequency and duration had unsurprisingly decreased in previously physically active individuals due to closure of gyms and health clubs, and reduced need for active commuting $[1,18,19]$. Individuals who engaged less and less often in PA during the pandemic had poorer wellbeing and mental health outcomes [16]. Similar links may exist and extended to adolescents and children. Regardless of PA reductions, the COVID-19 pandemic is in itself presents individuals with an unprecedented situation of unknown duration, which might create or/and enhance symptoms of anxiety, fear, depression, PTSD, anger, or sleep disruption [6,20-22].

In this extraordinary situation where public health measures have impacted habitual lifestyle practices, there are emerging data demonstrating COVID-19 confinement has influenced PA practice in the general population $[1,23]$. Yet, there are a paucity of data concerning team sport athletes, and particularly team handball players. Team handball, as with all other indoor team sports (e.g., basketball, ice hockey, volleyball), may be susceptible to PA changes as competition and training are mostly conducted in groups, which as banned as a result of social distancing measures, and the sport occurs indoors, and indoor facilities were closed in several countries. When active individuals, particularly well-trained athletes are confined to their homes, cardiorespiratory and neuromuscular fitness is likely lost [21].

Rapid changes in both the social environment and peoples' behaviors have negatively impacted wellbeing [24,25]. Physical inactivity, smoking, and obesity are among the risk factors of non-communicable diseases (NCDs) [25]. Hence, any negative implications on diet and physical activity from the pandemic-related disruptions are bound to aggravate the already dire situation. The lockdown had negative effects on emotional or mental states in some athletes [26,27]. However, it is not clear whether these conditions can be correlated with the type of sport (individual or collective), gender (male or female), or level (professional or non-professional). The earliest studies on athletes and COVID-19 [18] 
concluded that there were no differences between individual and collective sports, although Rubio et al. [18] showed higher levels of somatic symptoms in team players and faster rates of adaptation to isolation. Lorenzo Calvo et al. [28], reported isolation had an impact on the mental states of the Spanish Basketball athletes. Although lockdown was a novel phenomenon, the psychological problems it caused were similar to those experienced by athletes during longs periods of inactivity.

Due to lack of data concerning effects of PA in highly trained individuals and our previous studies on team handball players, we wanted to merge these to examine the effects home confinement had on PA, sedentary behavior, and satisfaction with life (SL) as a measure of the component of subjective wellbeing in team handball players from Europe and the Middle Eastern and North African (MENA) region during the COVID-19 restrictions. We hypothesized a priori that the pandemic restrictions during this time frame would reduce PA, increase sedentary behavior, and decrease life SL irrespective of playing level.

\section{Materials and Methods}

\subsection{Experimental Approach to the Problem}

We gathered 418 responses in this cross-sectional study using an online survey that consisted of the IPAQ Short Form (IPAQ-SF) and SL Questionnaire [29,30]. Both surveys were administered in English, German, French, Arabic, and Japanese on 27 July 2020 through six research institutes in Europe, North Africa and Western Asia The survey consisted of 25 questions capturing demographic information (handball-specific questions, health status, and PA. The survey consisted of 25 questions on demographic information (e.g., age, gender, body mass, and height), athletic status (e.g., defined as a person who competes in one or more activities that involve physical strength, speed, and/or endurance), smoking status, health status (e.g., anxiety or depression, diabetes, cardiovascular disease and pulmonary disease, and motor problem), PA (e.g., vigorous, moderate, and walking activity), and SL (e.g., life conditions, satisfaction with life, and important things for life). Questions were to be answered directly in sequence regarding "before" and "during" confinement conditions [31,32]. Measures were obtained on the same day to limit order or recall bias, considering the regularly evolving situation of the pandemic. Once the deadline for finalizing the survey passed, conflicting responses (inconsistency between data) and duplicated responses ( $\geq 2$ submissions with equivalent responses in a short period) were removed from the database. This experiment was conducted in line with the Declaration of Helsinki, and approved by Ethics committee of the university (protocol code QU-IRB 1350-EA / 20 and date of approval 22 July 2020 for local participants. The first renewal of the above QU-IRB is approved and it is renewed from 22 July 2021). Participants gave written consent prior to experiment start.

\subsection{Sample Size}

The sample size was calculated according to the following predictive equation [33].

$$
\mathrm{N}=((\mathrm{Z} \alpha / 22 \mathrm{p} \mathrm{q})) / \Delta 2
$$

$\mathrm{N}$ : number of needed participants,

$\mathrm{Z} \alpha / 2$ : two-tailed normal deviate for type 1 error,

$\mathrm{p}$ : change in \% from "before" to "during" confinement,

q: equal to " $1-\mathrm{p}$ " and $\Delta$ : accuracy; where " $\mathrm{n}$ " was the number of needed participants,

" $\mathrm{Z} \alpha / 2$ " was the two-tailed normal deviate for type 1 error $(\mathrm{Z} \alpha / 2=1.96$ for $95 \%$ level of significance),

"q" was equal to " $1-\mathrm{p}$ ",

" $\Delta$ " was the accuracy $(=3 \%)$, and

" $p$ " was the percentage of change in social participation from "before" to "during" confinement period. 
Comparable to Ammar et al. [34], the "p" was chosen from a study [35]. Zhang et al. [35] examined the immediate effects of the COVID-19 pandemic on mental health and quality of life. Based on these findings, it appeared that $57.8 \%(p=0.578)$ of subjects experienced an increase in shared feelings with family members [35]. Consequently, the calculated sample size for our investigation was $\mathrm{n}=418$. Based on comparable studies with participation rates from $92 \%$ [32] and $91 \%$ [36], we assumed a dropout rate of $10 \%(n=42)$. Therefore, we aimed to recruit 460 participants.

\subsection{Survey Development Promotion and Distribution}

A steering group of $\mathrm{PhD}$ scientists and academics (in the fields of human sciences, sport science, and computer science) designed the electronic survey at the University of Qatar (where the principal investigator was based). In addition, the survey was subsequently evaluated and amended by handball players, coaches and experts from the International Handball Federation (IHF). Thereafter, the survey was reviewed and edited by $>35$ colleagues and experts before being disseminated via the Google platform (online). Members of the consortium distributed the link to the survey via several methods: e-mail, official faculty pages, ResearchGate ${ }^{\mathrm{TM}}$, LinkedIn ${ }^{\mathrm{TM}}$, and other social media platforms such as Facebook ${ }^{\mathrm{TM}}$, WhatsApp ${ }^{\mathrm{TM}}$, and Twitter ${ }^{\mathrm{TM}}$. The general public assisted in the dissemination through promotion of the survey within their networks. In total, the uniform resource locator (URL) of the online survey was sent to potential participants.

\subsection{Data Privacy and Consent of Participation}

Participants were assured data would be used only for research purposes and answers were anonymous and confidential according to Google's privacy policy (https: / policies. google.com/privacy?hl=en accessed on 27 July 2020). Participants were able to withdraw participation and exit the IPAQ at any stage prior to submission without responses being saved. Responses were only saved when participants clicked a "submit" button. By completing the survey, participants acknowledged their voluntary consent to participate in this investigation. Participants were requested to be honest in their responses [1].

\subsection{International Physical Activity Questionnaire Short Form (IPAQ-SF)}

The International Physical Activity Questionnaire-SF (IPAQ-SF; [36]) apprised levels of PA, and data were equated within each item (i.e., vigorous intensity, moderate intensity, and walking) to estimate total weekly PA time $[29,30]$. According to the official IPAQ recommendations, data are summed within each item (i.e., vigorous intensity, moderate intensity, and walking) to estimate the total amount of time engaged in PA per week $[29,30]$. Weekly PA (MET-min $\cdot$ week $^{-1}$ ) was calculated by summing products of each PA item by a MET value specific to each category of PA. We assigned two sets of MET values. The first was the original values based on official IPAQ procedures for young and middleaged adults (18-65 years old): vigorous PA $=8.0$ METs, moderate PA $=4.0$ METs and walking = 3.3 METs [31]. Additionally, we added the total PA (sum of performed vigorous, moderate, and walking activity) as a fourth item and sitting time as the fifth item of sedentary behavior assessed using the question: "Since self-isolating, how much time have you spent sitting daily?".

\subsection{Satisfaction with Life Questionnaire}

The Satisfaction with Life Questionnaire (SL) questionnaire is a crisis-oriented 5 items 7-point scale (from 1; strongly disagree, to 7; strongly agree) questionnaire to investigate SL prior to and during confinement $[32,36,37]$. The total score of this questionnaire is comprised of the sum of scores from individual items. The total score for the SL questionnaire ranges from 5 to 35, with lower scores corresponding to extreme dissatisfaction and higher scores with extreme satisfaction [38]. 


\subsection{Statistical Analyses}

SPSS version 28.0 for Windows (SPSS Inc., IBM, Armonk, NY, USA) was used to perform statistical analyses. Shapiro-Wilk test was used to confirm normal distribution, and variance homogeneity was confirmed using Levene's test, justifying parametric data analyses. Differences between regions (MENA vs. Europe), playing positions (goalkeeper, back, wing, pivot, playmaker) and times (before vs. during confinement) were tested using a three-factor (region, position, time) analysis of variance (ANOVA) [39]. p-values and partial eta-squared $\left(\eta_{p}{ }^{2}\right)$ were calculated using the Greenhouse-Geisser Test [39]. Paired effect size (difference between means $\div$ pooled standard deviation [SD]) was calculated for each parameter [40]. The interpretation of effect sizes is based on Cohen's thresholds for small effects $(d<0.5)$, moderate effects $(d \geq 0.5)$ and large effects $(d>0.8)$ [41]. Effects were considered meaningful if $p<0.001, \eta_{p}{ }^{2}>0.10$ and the effect size (d) was $\geq 0.8$ [42]. The Bonferroni correction adjusted the $\mathrm{p}$ value based on the numbers of comparisons (e.g., PA parameter $\mathrm{p}$-values were divided by 15). Data are presented as mean $\pm \mathrm{SD}$.

\section{Results}

\subsection{Description of the Entire Sample}

$55 \%(231 / 418)$ participants (only men) were recruited in MENA and $45 \%$ were recruited in Europe (187/418). Most players played in the first league $(58 \%, \mathrm{n}=242$; Table 1$)$, $20 \%(n=83)$ in the second league, $15 \%$ in the third league $(n=64)$ and $7 \%$ in the fourth league $(n=29)$.

Table 1. Description of the sample $(n=418)$ regarding origin and handball activity.

\begin{tabular}{cccc}
\hline & & $\mathbf{n}$ & $\mathbf{\%}$ \\
\hline \multirow{3}{*}{ Level of handball league } & First & 242 & 58 \\
& Second & 83 & 20 \\
& Third & 64 & 15 \\
& Fourth & 29 & 7 \\
\hline \multirow{2}{*}{ Playing position } & Goalkeeper & 57 & 14 \\
& Back & 99 & 24 \\
& Pivot & 88 & 21 \\
& Wing & 104 & 25 \\
& Playmaker & 70 & 16 \\
\hline Playing experience (years) & & $12.3 \pm 6.71(2-35)$
\end{tabular}

Results reported as mean \pm standard deviation (range).

No effect of playing level (handball league) was observed for anthropometric variables (range of $\eta_{\mathrm{p}}^{2}: 0.002-0.036$ ).

No meaningful differences between the MENA and European region regarding demographic and anthropometric parameters were calculated. European participants were younger $\left(p=0.009, \eta_{\mathrm{p}}{ }^{2}=0.016, \mathrm{~d}=0.25\right)$, taller $\left(p=0.009, \eta_{\mathrm{p}}{ }^{2}=0.016, \mathrm{~d}=0.27\right)$ with a lower BMI $\left(p=0.033, \eta_{\mathrm{p}}{ }^{2}=0.011, \mathrm{~d}=0.08\right)$ and weight $\left(p=0.616, \eta_{\mathrm{p}}{ }^{2}=0.001, \mathrm{~d}=0.05\right)$ than MENA participants (Table 2).

The effect size of confinement for PA ranged from $\eta_{p}{ }^{2}=0.678$ (walking days/walk for at least $10 \mathrm{~min}$ ) to $\eta_{\mathrm{p}}{ }^{2}=0.858$ (vigorous MET-minutes per week; Table 3).

\subsection{The Effects Home Confinement on PA, Sedentary Behavior, and Satisfaction with Life (SL)}

The within group magnitude of change was similar in MENA $(d=3.29)$ and Europe $(\mathrm{d}=3.41)$. Between groups, differences between MENA and Europe were detected for $62 \%$ $(8 / 13)$ of the investigated parameters (Table 3$)$. However, no interaction effects (league $x$ time, position $x$ time, region $x$ time) were observed (Table 4$)$. The interaction effects (Table 4) ranged from $\eta_{\mathrm{p}}{ }^{2}=0.000$ to 0.094 (region), from $\eta_{\mathrm{p}}{ }^{2}=0.001$ to 0.024 (playing position, Figure 1) and from $\eta_{p}{ }^{2}=0.006$ to 0.078 (playing level, Figure 2). 
Table 2. Demographic and anthropometric characteristics of all participants $(n=418)$.

\begin{tabular}{cccc}
\hline & Total & MENA & Europe \\
\cline { 2 - 4 } & $(\mathbf{n}=\mathbf{4 1 8})$ & $\mathbf{( n = 2 3 1 )}$ & $\mathbf{( n = 1 8 7 )}$ \\
\hline \multirow{2}{*}{ Age $(\mathrm{yr})$} & $25.6 \pm 6.77$ & $26.4 \pm 6.83$ & $24.7 \pm 6.59$ \\
& $(15-60)$ & $(15-46)$ & $(17-60)$ \\
\hline \multirow{2}{*}{ Height $(\mathrm{m})$} & $1.83 \pm 0.08$ & $1.82 \pm 0.07$ & $1.84 \pm 0.08$ \\
& $(1.60-2.20)$ & $(1.60-2.00)$ & $(1.67-2.20)$ \\
\hline \multirow{2}{*}{ Weight $(\mathrm{kg})$} & $88.1 \pm 11.7$ & $88.4 \pm 12.4$ & $87.8 \pm 10.8$ \\
& $(55-133)$ & $(55-133)$ & $(60-123)$ \\
\hline \multirow{2}{*}{ Body mass index $\left(\mathrm{kg} / \mathrm{m}^{2}\right)$} & $26.3 \pm 3.62$ & $26.6 \pm 3.85$ & $25.9 \pm 3.28$ \\
& $(16.9-43.4)$ & $(17.2-43.4)$ & $(16.9-36.6)$ \\
\hline
\end{tabular}

Results reported as mean \pm standard deviation (range).

Table 3. Comparison of PA parameters between MENA region and Europe before and during confinement. Values are given as mean \pm SD. Meaningful effects (criteria: $p<0.05$ and $\eta_{p}{ }^{2}>0.10$ and $d>0.8$ ) highlighted in bold.

\begin{tabular}{|c|c|c|c|c|c|c|c|c|}
\hline & \multicolumn{3}{|c|}{ MENA $(n=231)$} & \multicolumn{3}{|c|}{ Europe $(n=187)$} & \multicolumn{2}{|c|}{ Variance Analysis/Effects $p\left(\eta_{\mathrm{p}}{ }^{2}\right)$} \\
\hline & Before & During & d & Before & During & d & Region & Time \\
\hline \multicolumn{9}{|c|}{ Vigorous PA } \\
\hline Days/week (d) & $4.59 \pm 0.93$ & $2.25 \pm 0.78$ & 2.74 & $5.13 \pm 0.89$ & $3.16 \pm 1.13$ & 1.95 & $<0.001(0.21)$ & $<0.001(0.76)$ \\
\hline Minutes/week (min) & $64.7 \pm 8.34$ & $36.4 \pm 12.2$ & 2.76 & $76.1 \pm 8.67$ & $47.0 \pm 13.1$ & 2.67 & $<0.001(0.32)$ & $<0.001(0.80)$ \\
\hline MET-minutes/week & $2384 \pm 608$ & $669 \pm 349$ & 3.58 & $3128 \pm 664$ & $1231 \pm 656$ & 2.87 & $<0.001(0.36)$ & $<0.001(0.85)$ \\
\hline \multicolumn{9}{|c|}{ Moderate PA } \\
\hline Days/week (d) & $4.81 \pm 0.89$ & $2.56 \pm 0.77$ & 2.71 & $4.63 \pm 0.90$ & $2.74 \pm 0.75$ & 2.29 & $0.918(0.00)$ & $<0.001(0.79)$ \\
\hline Minutes/week (min) & $62.8 \pm 9.89$ & $42.9 \pm 11.3$ & 1.88 & $70.1 \pm 7.00$ & $41.4 \pm 12.2$ & 2.99 & $<0.001(0.03)$ & $<0.001(0.76)$ \\
\hline MET-minutes/week & $1208 \pm 289$ & $436 \pm 180$ & 3.29 & $1299 \pm 294$ & $460 \pm 198$ & 3.41 & $<0.001(0.03)$ & $<0.001(0.86)$ \\
\hline \multicolumn{9}{|c|}{ Walking } \\
\hline Days/walk for at least $10 \mathrm{~min}$ (d) & $4.44 \pm 0.93$ & $2.43 \pm 0.79$ & 2.34 & $4.82 \pm 1.14$ & $2.84 \pm 1.32$ & 1.61 & $<0.001(0.06)$ & $<0.001(0.68)$ \\
\hline Minutes per walking day (min) & $59.5 \pm 10.3$ & $28.6 \pm 10.7$ & 2.94 & $75.9 \pm 10.1$ & $39.4 \pm 13.0$ & 3.16 & $<0.001(0.42)$ & $<0.001(0.83)$ \\
\hline MET-minutes/week & $868 \pm 227$ & $231 \pm 130$ & 3.57 & $1209 \pm 328$ & $382 \pm 243$ & 2.90 & $<0.001(0.33)$ & $<0.001(0.84)$ \\
\hline \multicolumn{9}{|c|}{ Sitting } \\
\hline hours per weekday day (h) & $2.48 \pm 0.75$ & $4.89 \pm 0.91$ & 2.90 & $2.57 \pm 0.80$ & $4.79 \pm 0.95$ & 2.54 & $0.937(0.00)$ & $<0.001(0.80)$ \\
\hline
\end{tabular}

Table 4. Satisfaction with life parameters before and during confinement. Values are given as mean \pm standard deviation. Meaningful effects are in bold font.

\begin{tabular}{|c|c|c|c|c|c|c|c|c|c|}
\hline & \multicolumn{3}{|c|}{ MENA $(n=231)$} & \multicolumn{3}{|c|}{ Europe $(n=187)$} & \multicolumn{3}{|c|}{ Variance Analysis/Effects $p\left(\eta_{\mathrm{p}}{ }^{2}\right)$} \\
\hline & Before & During & d & Before & During & d & Region & Time & Region $\times$ Time \\
\hline \multicolumn{10}{|c|}{ In most ways my life is close to my ideal } \\
\hline Score Q1 & $30.0 \pm 4.60$ & $13.1 \pm 3.22$ & 4.32 & $26.8 \pm 5.93$ & $13.9 \pm 6.21$ & 2.13 & $<0.001(0.03)$ & $<0.001(0.81)$ & $<0.001(0.08)$ \\
\hline \multicolumn{10}{|c|}{ The conditions of my life are excellent. } \\
\hline Score Q2 & $32.5 \pm 2.91$ & $12.2 \pm 2.74$ & 7.19 & $31.4 \pm 4.07$ & $14.4 \pm 5.56$ & 3.53 & $0.031(0.01)$ & $<0.001(0.91)$ & $<0.001(0.07)$ \\
\hline \multicolumn{10}{|c|}{ I am satisfied with my life } \\
\hline Score Q3 & $30.0 \pm 4.37$ & $16.3 \pm 4.86$ & 2.97 & $30.5 \pm 3.63$ & $11.8 \pm 6.51$ & 3.69 & $<0.001(0.07)$ & $<0.001(0.85)$ & $<0.001(0.12)$ \\
\hline \multicolumn{10}{|c|}{ So far I have gotten the important things I want in life. } \\
\hline Score Q4 & $31.2 \pm 4.48$ & $13.4 \pm 2.57$ & 5.05 & $29.5 \pm 3.11$ & $14.3 \pm 4.64$ & 3.92 & $0.096(0.01)$ & $<0.001(0.90)$ & $<0.001(0.05)$ \\
\hline \multicolumn{10}{|c|}{ If I could live my life over, I would change almost nothing. } \\
\hline Score Q5 & $32.4 \pm 3.05$ & $16.0 \pm 4.41$ & 4.40 & $31.5 \pm 3.69$ & $13.0 \pm 6.38$ & 3.67 & $<0.001(0.10)$ & $<0.001(0.87)$ & $<0.002(0.02)$ \\
\hline \multicolumn{10}{|c|}{ Total score } \\
\hline & $31.2 \pm 2.14$ & $14.2 \pm 1.89$ & 8.44 & $29.9 \pm 1.60$ & $13.5 \pm 2.47$ & 8.06 & $<0.001(0.10)$ & $<0.001(0.97)$ & $0.036(0.01)$ \\
\hline
\end{tabular}




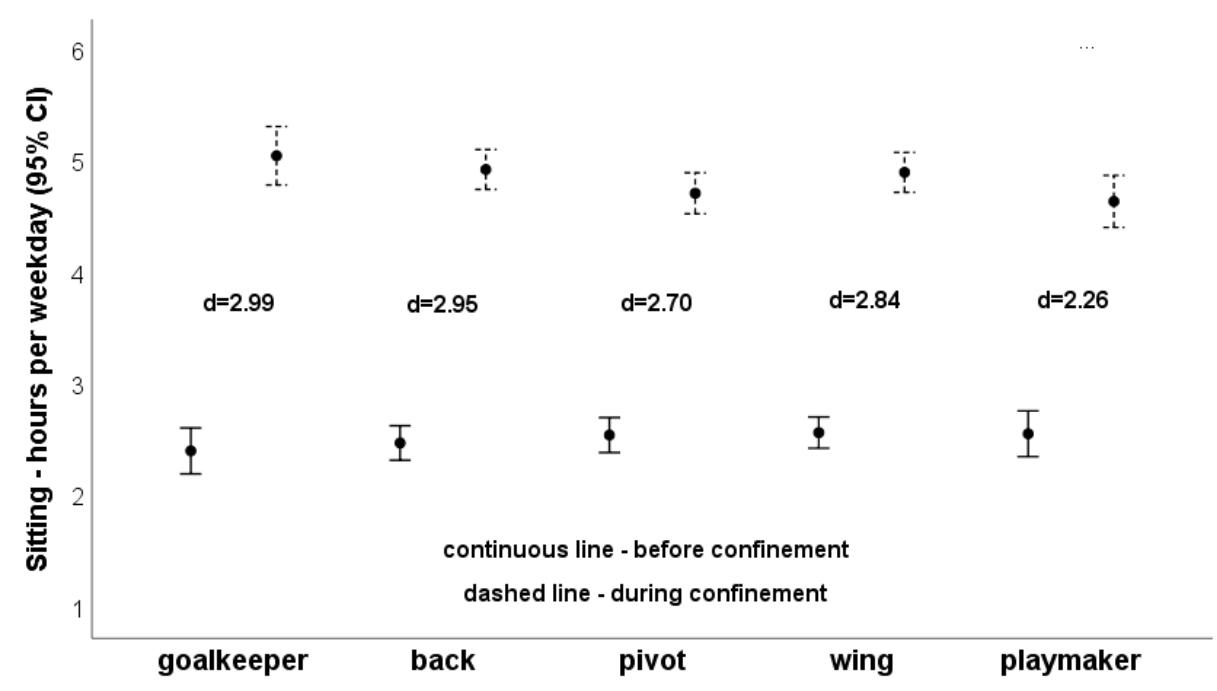

Figure 1. Sitting hours per weekday depending on playing positions.

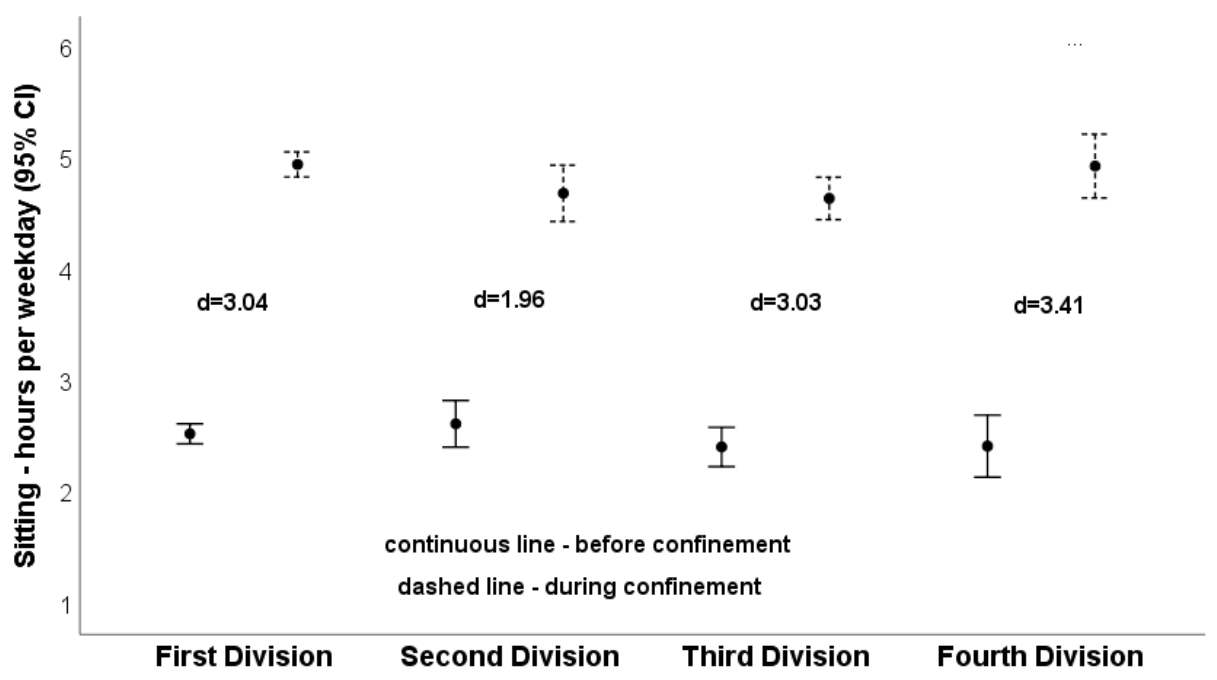

Figure 2. Sitting hours per weekday depending on level of handball league.

No relevant correlations $(\mathrm{r}>0.5)$ were calculated between physical activity and satisfaction with life parameters based on the values before confinement. The variance analysis of "satisfaction with life" parameters (Table 4) showed only one interaction (region x time) effect $\left(\eta_{p}{ }^{2}=0.12\right)$ for the item "I am satisfied with my life". The time effects were consistently large and differed from $\eta_{\mathrm{p}}{ }^{2}=0.81$ (In most ways my life is close to my ideal) to $\eta_{\mathrm{p}}{ }^{2}=0.97$ (total score). Region effects at examination 1 were only observed for the total score $\left(\eta_{\mathrm{p}}{ }^{2}=0.10\right)$ and the item "If I could live my life over, I would change almost nothing." $\left(\eta_{\mathrm{p}}^{2}=0.10\right)$.

Very large effect sizes were calculated for all satisfaction with life items (Table 4). The effect sizes $d$ for the scores (Q1 to Q5) ranged from $d=2.97$ (Q3/MENA) to $d=7.19$ (Q2/MENA) as a sign of a strongly reduction of quality of life.

There were no interaction effects (Table 5) of region (range of $\eta_{\mathrm{p}}{ }^{2}: 0.000-0.09$ ), playing position (range of $\eta_{\mathrm{p}}{ }^{2}: 0.00-0.02$; Figure 1) or playing level (range of $\eta_{\mathrm{p}}{ }^{2}: 0.01-0.08$; Figure 2). 
Table 5. Comparison of PA parameters depending on playing level (handball league), playing position, and region. Meaningful interaction effects (criteria: $p<0.05$ and $\eta_{\mathrm{p}}{ }^{2}>0.10$ ) highlighted in bold.

\begin{tabular}{|c|c|c|c|}
\hline \multirow{2}{*}{ Variables } & \multicolumn{3}{|c|}{ Variance Analysis/Interaction Effects $p\left(\eta_{\mathrm{p}}{ }^{2}\right)$} \\
\hline & League $\times$ Time & Position $\times$ Time & Region $\times$ Time \\
\hline \multicolumn{4}{|c|}{ Vigorous PA } \\
\hline Days/week (d) & $<0.001(0.08)$ & $0.085(0.02)$ & $0.003(0.02)$ \\
\hline Minutes/week (min) & $0.369(0.01)$ & $0.488(0.02)$ & $0.580(0.00)$ \\
\hline MET-minutes/week & $<0.001(0.05)$ & $0.282(0.01)$ & $0.013(0.02)$ \\
\hline \multicolumn{4}{|c|}{ Moderate PA } \\
\hline Days/week (d) & $0.981(0.00)$ & $0.623(0.01)$ & $0.001(0.03)$ \\
\hline Minutes/week (min) & $0.247(0.01)$ & $0.150(0.02)$ & $<0.001(0.09)$ \\
\hline MET-minutes/week & $0.463(0.01)$ & $0.758(0.01)$ & $0.036(0.01)$ \\
\hline \multicolumn{4}{|c|}{ Walking } \\
\hline Days/walk for at least $10 \mathrm{~min}(\mathrm{~d})$ & $0.082(0.02)$ & $0.987(0.00)$ & $0.792(0.00)$ \\
\hline Minutes per walking day (min) & $0.443(0.01)$ & $0.260(0.01)$ & $<0.001(0.03)$ \\
\hline MET-minutes week & $0.305(0.01)$ & $0.856(0.00)$ & $<0.001(0.08)$ \\
\hline \multicolumn{4}{|c|}{ Sitting } \\
\hline hours per weekday & $0.081(0.02)$ & $0.038(0.02)$ & $0.096(0.01)$ \\
\hline
\end{tabular}

Based on the change in PA from before to during confinement measured by $\Delta \mathrm{d}$ and $\eta_{\mathrm{p}}{ }^{2}$, moderate PA (minutes/week) demonstrated the largest group difference $(\Delta \mathrm{d}=1.11$, $\left.\eta_{\mathrm{p}}{ }^{2}=0.86\right)$. The smallest change $\left(\Delta \mathrm{d}, \eta_{\mathrm{p}}{ }^{2}\right)$ over the time was observed for walking (days/walk for at least $10 \mathrm{~min}: \Delta \mathrm{d}=0.73, \eta_{\mathrm{p}}{ }^{2}=0.678$ ). The effect sizes for both samples (Europe vs. MENA) were similar $\left(\mathrm{d}_{\text {MENA }}=2.34, \mathrm{~d}_{\text {Europe }}=1.61\right.$; Table 3$)$.

A detailed variance analysis based on the 23 involved countries (number of subjects range: 1-86) was only possible and senseful for countries/samples with more than 30 subjects. Five countries fulfilled the criterion: Kuwait $(n=86)$, Saudi Arabia $(n=55)$, Iraq $(n=39)$, Romania $(n=50)$, Germany $(n=37)$, France $(n=31)$. Regarding demographic and anthropometric parameters only the age $\left(p<0.001, \eta_{\mathrm{p}}{ }^{2}=0.179\right)$ was different between countries. The mean age ranged from 22.0 years (Romania) to 31.5 years (Iraq). The comparison of physical activity parameters between countries before and during confinement revealed interaction effects (time $\times$ country) for four parameters (Table 6).

Table 6. Comparison of physical activity parameters between countries before and during confinement. Meaningful interaction effects (criteria: $p<0.05$ and $\eta_{\mathrm{p}}{ }^{2}>0.10$ ) highlighted in bold.

\begin{tabular}{ccc}
\hline Acitivities & Parameters & Interaction Effects (Time $\times$ Country) \\
$p\left(\eta_{\mathrm{p}}{ }^{2}\right)$ & $<0.001(0.29)$ \\
& Days/week (d) & $0.102(0.03)$ \\
Vigorous physical activities & Minutes/week (min) & $<.001(0.19)$ \\
& MET-minutes/week & $<0.001(0.07)$ \\
Moderate physical activities & Days/week (d) & $<0.001(0.11)$ \\
& Minutes/week (min) & $<0.001(0.08)$ \\
\hline \multirow{2}{*}{ Walking } & MET-minutes/week & $<0.001(0.07)$ \\
& Days/walk for at least 10 min (d) & $<0.001(0.07)$ \\
\hline Sitting & Minutes per walking day (min) & $<0.001(0.13)$ \\
\hline
\end{tabular}

The largest interaction effect $\left(\eta_{p}{ }^{2}=0.285\right)$ was displayed for vigorous PA (days/week) (Figure 3). The effect sizes d ranged from 0.78 (Romania) to 4.09 (Germany). 


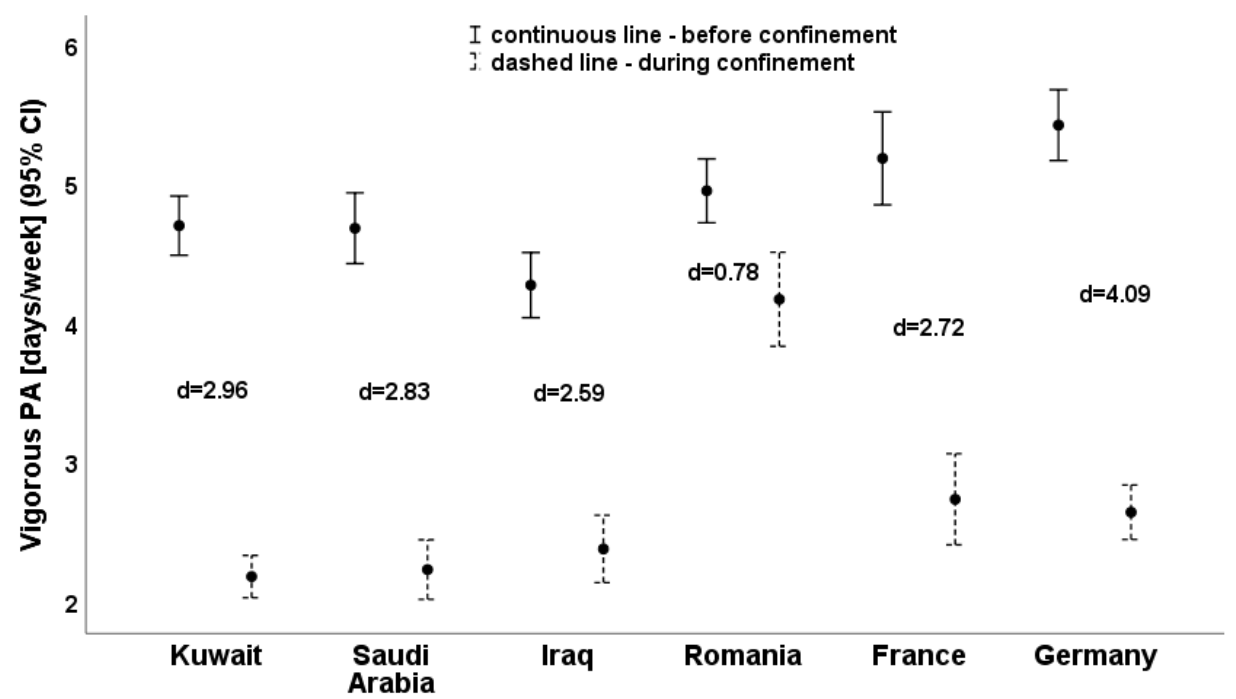

Figure 3. Vigorous PA (days per week) depending on the five countries with the largest sample size.

\section{Discussion}

Results of the present experiment suggest COVID-19 home confinement caused a meaningful reduction in PA and increased sitting time regardless of competition level and region in team handball. Furthermore, there were some reductions in PA in handball training at intensive and moderate level during home confinement. The greatest difference between MENA and European participants was in the parameter moderate PA minutes/week. The smallest regional difference was observed for walking and both paired effect sizes were comparable. Based on the total score and the whole sample, the quality of life decreased. The loss of quality of life over the time was similar in both regions. The negative impact COVID-19 pandemic has had upon social participation and life satisfaction during home confinement was evident in our present investigation that support the contention there is significant psychosocial burden resulting from this home confinement.

\subsection{Reasons of Decreased of Physical Activity}

Team handball is of considerable internal load because of repeated high-intensity actions [43-45]. The number of body contacts perceivably increases neuromuscular load, and subsequent fatigue, both during and following games [46]. Therefore, imitating game intensity in daily team handball training is important to mimic demands of match play. In general, players from lower divisions and amateurs usually practice handball training for three or four times a week for about $2 \mathrm{~h}$ per session [47]. Professional or aspiring professionals spend approximately $11 \mathrm{~h}$ per week $(5-6 \times \sim 2 \mathrm{~h})$ on training in the handball court and $3 \mathrm{~h}(2 \times \sim 1.5 \mathrm{~h})$, at the gym. Furthermore, they have weekly competitive matches, seasonally dependent $[44,45]$.

This experiment demonstrated that daily volume of PA decreased during home confinement at vigorous intensity by $49 \%$ in MENA and $62 \%$ in Europe, which result in reduced training stimulus and thus losses in fitness. Although we were unable to quantify reductions in fitness, Fikenzer et al. [47] reported reduced aerobic capacity of elite handball players in the absence of training, despite players being provided with a home-based exercise program.

Recent multicenter studies showed that COVID-19 home confinement increased the numbers of physically inactive individuals $(+15 \%)$ [48]. However, the study of Hermassi et al. [36], the number of walking days for at least 10 min per week decreased of $\sim 35 \%$ in both genders. Concomitantly, time per walk decreased of $46 \%$ in both genders. Therefore, the energy expenditure of walking per week decreased from $449 \pm 261$ MET-minutes/week to $141 \pm 87.0$ MET-minutes/week for women and from $528 \pm 271$ MET-minutes/week to $215 \pm 120$ MET-minutes/week in men. 
Ammar et al. [49] reported after an international online survey was launched in April 2020 that the number of days/week of walking decreased by 35\% during home confinement $(\mathrm{t}=15.80, p<0.001, \mathrm{~d}=0.68)$. Likewise, the same study reported that the number of minutes/day of walking decreased by $34 \%$ during home confinement $(\mathrm{t}=9.34$, $p<0.001, \mathrm{~d}=0.39)$. Additionally, MET values of walking were $43 \%$ lower during home confinement $(\mathrm{t}=9.03, p<0.001, \mathrm{~d}=0.36)$. It is important to mention here that the studies were all developed during the cool weather, which make comparison easier between populations from North Africa, Europe, and Asia.

In terms of competition level, our findings corroborate those of Mon-López et al. [17] who noted a greater reduction in training time of professional handball players than nonprofessionals. Moreover, Skoufas et al. [46] observed a similar phenomenon in that higher competitive level athletes reduced their volume of training to a greater extent than others during off-season or non-competitive periods. This is likely in part due to the higher initial levels of PA, and thus a greater reduction in non-competitive periods or confinement conditions would be expected.

Both Mon-López et al. [17] and Giustino et al. [14] have reported a greater reduction in volume of training in males than in females during confinement conditions. However, in the present investigation when we considered thee interaction effect of gender and competitive level, professional female players reduced training more than their male counterparts. Mon-López et al. [17] suggested this may be manifest as a result of disproportion participant numbers $47 \%$ females in were professional whereas only $38 \%$ of the males were professional). This may have profound effects on fitness and injury risk as a recent investigation noted male semi-professional football players decreased hamstring muscle strength during home confinement only after 25 days [50].

Hermassi et al. [32] reported in team handball Worldwide Study that home confinement by COVID-19 caused a decrease in the amount of walking per week and an increase in sitting time, which reflects PA in daily life. In addition, the amount of PA at vigorous and moderate intensity, which mostly reflected PA in handball training for handball players, decreased during COVID-19 home confinement. In addition, indicate that COVID-19-induced home confinement affected not only daily life activities but also PA at moderate and vigorous intensity, which is essential for team handball players to maintain and improve their physiological capacities, and therefore, performance as handball players at all levels of performance. The PA of handball players was not affected by continent (5), country (29), gender, level of handball league, and playing position.

This study confirms results of recent investigations demonstrating the negative and dramatical influences COVID-19 home confinement has on participation of sporting activities and PA engagement $[1,37]$. Restrictions associated with the pandemic reduced total PA (number of days and hours per week). Despite the increased PA offered online via social media, data presented here indicate team handball players were unable to maintain their usual PA patterns appropriately during the measures. Decreased PA was followed by increase in sedentary behavior (sitting time) in this investigation but the largest detected changes across all parameters were for the sum parameter "total PA".

The energy expenditure (MET-minutes/week) decreased compared to before confinement. These data contradict those in a Canadian population. A survey measuring PA levels of Canadian adults [51] during lockdown demonstrated that MVPA was not altered by lockdown restrictions in people with a pre-existing high MVPA volume. This may be due to individual differences in PA for recreation and health promotion in the Canadian population and competitive sports people in the present sample. People who undertake PA recreationally may be able to continue during lockdown because they consist primarily of outdoor activities, possibly in rural areas. Conversely, subjects in this study were handball players and PA at vigorous and moderate intensities could be obtained solely through training handball in the indoor training facilities. Handball matches were cancelled, and indoor training facilities were closed to prevent the spread of COVID-19. 


\subsection{Impact COVID-19 on Life Satisfaction}

COVID-19 produced an unprecedented worldwide mental health emergency [21] and the restrictive measures, although necessary to ameliorate infection may lead to physical and mental challenges for athletes [52], including increased fear of contracting COVID-19 [53], rumination [34], anxiety and depression [54], sleep and eating disorders [48], psychological inflexibility [55], sedentary lifestyle and negative habits [56], low mood [1]. Few sport psychologists and coaches have highlighted the negative effects restrictive public health measures might pose on SL and noted athletes have been diagnosed with several psychological disorders recently [34].

No relevant correlations were observed between PA and SL before confinement. Variance analysis of SL parameters showed only one interaction (region $x$ time) effect for the item "I am satisfied with my life". Time effects were consistently large and ranged from $\eta_{p}{ }^{2}=0.81$ (In most ways my life is close to my ideal) to $\eta_{p}{ }^{2}=0.97$. Region effects pre-pandemic were only observed for the total score and the item "If I could live my life over, I would change almost nothing". The fear of being infected by COVID-19 as well with stress produced by restrictive isolation measures have been negatively related to people's SL [34,49,54-56]. These data support those of Ammar et al. [49] who reported the negative effects confinement had on mental health, mood, and feelings with more people $(+13 \%)$ exhibiting lower mental wellbeing during confinement compared to pre-pandemic.

There are multiple credible explanations for decreased SL observed in this investigation. The current pandemic has unquestionably created loss and fear for many individuals, and elite athletes. Specifically, those athletes that have lost employment, social relationships, and opportunities to compete in national and international competitions.

\subsection{Implications and Good Practice}

A recommendation emanating from results of the present investigation is that it is imperative to provide competitive handball players with a definitive exercise program to ameliorate detraining prior to return to play [32]. According to Toresdahl and Asif [57], athletes should follow a conventional approach during this time to prevent COVID-19 with training sessions of $<60 \mathrm{~min}$ and to $<80 \%$ of maximum effort. By contrast, HerreraValenzuela et al. [58] endorsed that individuals can perform high-intensity interval training (HIIT) at home to sustain physical fitness.

\subsection{Limitations}

This study is not without limitations, which we accept. First, we did not question participants about their place of exercise due to the gathering data rapidly. However, we assumed participants in this experiment would not be able to take part in team training and matches inside training facilities, but might use their home and/or backyard for individual training purposes due to lockdown restrictions.

The main limitation in this study however, as with all self-reporting, is the possibility of reporting bias of PA (overestimation of PA), which is common among the respondents of a self-reported questionnaire. However, we have asked the same questions in the survey about the two different periods (before and during home confinement by COVID-19). Thus, we speculate that the degree of bias is similar based on internal consistency of respondents. It is also possible that recall bias was manifest, and respondents were unable to correctly recall the amount of PA before confinement. This is an innate problem with all self-reporting and recall data. Without the power of foresight, it is impossible to avoid recall bias if asking participants about a previous time period. However, one way to ameliorate the influence of recall and reporting bias is to use the athletes' 'wearables' to objectively and retrospectively determine changes in PA over specific time periods. However, as described in our recent article (REF), there are still significant hurdles to this approach, namely skills in computer science and web protocols, approval for data access from multiple stakeholders, between-device variation, and resource commitment. Thus, we feel our approach in the present study was justified at time of writing. We are hopeful 
that in the future, objective, valid, population level PA patterns will be more easily accessed through consumer-grade wearable devices.

Additionally, data concerning mode of exercise (i.e., cycle or running, resistance training), and confinement nuances based on country of residence would add depth to this study and should be considered in future studies. Additionally, although our sample was exclusively handball players, the tool for PA data collection was not specifically designed for this population, and was intended for the general population, so more nuanced data are not possible.

Reporting satisfaction (LS) regarding life before and during the pandemic may be affected by recall biased due to different problems (e.g., stress) or diseases (e.g., depression). This impairs the meaningfulness of the results.

Finally, data collection was via questionnaires with subjective ratings and this has not been validated by objective indicators. Therefore, we strongly recommend conducting an indirect calorimetry or doubly labelled water to measure physical activity during $24 \mathrm{~h}$ to enhance validity of the results.

\section{Conclusions}

Confinement decrease PA and LS regardless of region, handball playing level, and playing position. Results indicate home confinement induced deleterious effect on PA and LS. For example, increased sitting time indicative of a more sedentary lifestyle as an indicator for worse living conditions and low life satisfaction. There is a need to translate these findings to help inform future recommendations for home-based exercise in team handball players for PA participation to sustain HEPA active category during and after the COVID-19 pandemic. To alleviate the adverse psychosocial effects resulting of home confinement, the exertion of social inclusion has been the focus of national and international efforts.

Author Contributions: Conceptualization, R.S. and S.H.; methodology, S.H.; software, S.H.; validation, R.S.; formal analysis, L.D.H. and S.H.; investigation, S.H.; resources, S.H.; data curation, S.H.; writing—original draft preparation, S.H., R.S. and L.D.H.; writing—review and editing, N.E.M.S.-H., L.D.H. and R.S.; visualization, R.S.; supervision, L.D.H., and S.H.; project administration, S.H.; funding acquisition, R.S. and S.H. All authors have read and agreed to the published version of the manuscript.

Funding: This research received no external funding.

Institutional Review Board Statement: The study was conducted according to the guidelines of the Declaration of Helsinki, and approved by the Institutional Review Board of QATAR UNIVERSITY (protocol code QU-IRB 1350-EA/20 and date of approval 22 July 2020 for local participants. The first renewal of the above QU-IRB is approved and it is renewed from 22 July 2021).

Informed Consent Statement: Informed consent was obtained from all subjects involved in the study.

Data Availability Statement: The raw data supporting the conclusions of this article will be made available by the authors without undue reservation.

Acknowledgments: We thank our colleagues who provided insight and expertise that greatly assisted the research. We thank all colleagues and people who believed in this initiative and helped to distribute the anonymous survey worldwide especially the International Handball Federation Experts and Lectures: Jochen Beppler, (GER); Boubekeur Zermani (GER); Ilona Hapkova (Czech Republic); Nabeel Taha Al Shehab (Bahrain); Serdar Eler (Turkey) and Eoin Murray (New Zealand). We are also immensely grateful to all players for their contribution to the study.

Conflicts of Interest: The authors declare no conflict of interest. 


\section{References}

1. Ammar, A.; Brach, M.; Trabelsi, K.; Chtourou, H.; Boukhris, O.; Masmoudi, L.; Bouaziz, B.; Bentlage, E.; How, D.; Ahmed, M.; et al. Effects of COVID-19 Home Confinement on Eating Behaviour and Physical Activity: Results of the ECLB-COVID1 International Online Survey. Nutrients 2020, 12, 1583. [CrossRef] [PubMed]

2. Hawkley, L.C.; Capitanio, J.P. Perceived social isolation, evolutionary fitness and health outcomes: A lifespan approach. Philos. Trans. R. Soc. Lond. Ser. B Biol. Sci. 2015, 370, 20140114. [CrossRef] [PubMed]

3. Kiecolt-Glaser, J.K.; McGuire, L.; Robles, T.F.; Glaser, R. Emotions, morbidity, and mortality: New perspectives from psychoneuroimmunology. Annu. Rev. Psychol. 2002, 53, 83-107. [CrossRef] [PubMed]

4. Chen, P.; Mao, L.; Nassis, G.P.; Harmer, P.; Ainsworth, B.E.; Li, F. Coronavirus disease (COVID-19): The need to maintain regular physical activity while taking precautions. J. Sport Health Sci. 2020, 9, 103-104. [CrossRef]

5. Lau, H.M.-C.; Lee, E.W.-C.; Wong, C.N.-C.; Ng, G.Y.-F.; Jones, A.Y.-M.; Hui, D.S.C. The Impact of Severe Acute Respiratory Syndrome on the Physical Profile and Quality of Life. Arch. Phys. Med. Rehabil. 2005, 86, 1134-1140. [CrossRef]

6. Altena, E.; Baglioni, C.; Espie, C.A.; Ellis, J.; Gavriloff, D.; Holzinger, B.; Schlarb, A.; Frase, L.; Susanna, J.; Riemann, D. Dealing with sleep problems during home confinement due to the COVID-19 outbreak: Practical recommendations from a task force of the European CBT-I Academy. J. Sleep Res. 2020, 4, e13052. [CrossRef]

7. Ning, L.; Niu, J.; Bi, X.; Yang, C.; Liu, Z.; Wu, Q.; Ning, N.; Liang, L.; Liu, A.; Hao, Y.; et al. The impacts of knowledge, risk perception, emotion and information on citizens' protective behaviors during the outbreak of COVID-19: A cross-sectional study in China. BMC Public Health 2020, 20, 1751. [CrossRef]

8. Scales, P.C. The crucial coaching relationship. Phi Delta Kappan 2016, 97, 19-23. [CrossRef]

9. Galán, J.M.S.; Calvo, A.L.; Saiz, S.L.J.; Calvo, J.L. The coach as youth players' mentor: Study of positive coach-athlete relationships. Rev. Psicol. Deporte 2017, 26, 95-99.

10. Jowett, S.; Poczwardowskia, A. Social Psychology in Sport. In Understanding the Coach-Athlete Relationship; Jowette, S., Lavallee, D., Eds.; Human Kinetics: Champaign, IL, USA, 2007; pp. 3-13.

11. Li, J.; Gao, H.; Liu, P.; Zhong, C. Does Distance Produce Beauty? The Influence of COVID-19 Lockdown on the Coach-Athlete Relationship in a Chinese Football School. Front. Psychol. 2020, 11, 560638. [CrossRef]

12. Arora, T.; Grey, I. Health behaviour changes during COVID-19 and the potential consequences: A mini-review. J. Health Psychol. 2020, 25, 1155-1163. [CrossRef]

13. Schuch, F.B.; Bulzing, R.A.; Meyer, J.; Vancampfort, D.; Firth, J.; Stubbs, B.; Grabovac, I.; Willeit, P.; Tavares, V.D.O.; Calegaro, V.C.; et al. Associations of moderate to vigorous physical activity and sedentary behavior with depressive and anxiety symptoms in self-isolating people during the COVID-19 pandemic: A cross-sectional survey in Brazil. Psychiatry Res. 2020, $292,113339$. [CrossRef]

14. Giustino, V.; Parroco, A.M.; Gennaro, A.; Musumeci, G.; Palma, A.; Battaglia, G. Physical Activity Levels and Related Energy Expenditure during COVID-19 Quarantine among the Sicilian Active Population: A Cross-Sectional Online Survey Study. Sustainability 2020, 12, 4356. [CrossRef]

15. López-Bueno, R.; Calatayud, J.; Andersen, L.L.; Balsalobre-Fernández, C.; Casaña, J.; Casajús, J.A.; Smith, L.; Lopez-Sanchez, G.F. Immediate impact of the COVID-19 confinement on physical activity levels in Spanish adults. Sustainability 2020, $12,5708$. [CrossRef]

16. Dönmez, G.; Özkan, Ö.; Menderes, Y.; Torgutalp, Ş.Ş.; Karaçoban, L.; Denerel, N.; Kudaş, S. The effects of home confinement on physical activity level and mental status in professional football players during COVID-19 outbreak. Phys. Sportsmed. 2021, 21, 1-7. [CrossRef]

17. Mon-Lopez, D.; de la Rubia Riaza, A.; Hontoria Galan, M.; Refoyo Roman, I. The impact of Covid-19 and the effect of psychological factors on training conditions of handball players. Int. J. Environ. Res. Public Health 2020, 17, 6471. [CrossRef]

18. Rubio, V.J.; Sánchez-Iglesias, I.; Bueno, M.; Martin, G. Athletes' Psychological Adaptation to Confinement Due to COVID-19: A Longitudinal Study. Front. Psychol. 2021, 11, 613495. [CrossRef]

19. Wilson, O.W.A.; Holland, K.E.; Elliott, L.D.; Duffey, M.; Bopp, M. The Impact of the COVID-19 Pandemic on US College Students' Physical Activity and Mental Health. J. Phys. Act. Health 2021, 18, 272-278. [CrossRef]

20. Brooks, S.K.; Webster, R.K.; Smith, L.E.; Woodland, L.; Wessely, S.; Greenberg, N.; Rubin, G.J. The psychological impact of quarantine and how to reduce it: Rapid review of the evidence. Lancet 2020, 395, 912-920. [CrossRef]

21. Fuentes-García, J.P.; Martínez Patiño, M.J.; Villafaina, S.; Clemente-Suárez, V.J. The effect of COVID-19 confinement in behavioral, psychological, and training patterns of chess players. Front. Psychol. 2020, 11, 1812. [CrossRef]

22. Bridgland, V.M.E.; Moeck, E.K.; Green, D.M.; Swain, T.L.; Nayda, D.M.; Matson, L.A.; Hutchison, N.P.; Takarangi, M.K.T. Why the COVID-19 pandemic is a traumatic stressor. PLOS ONE 2021, 16, e0240146. [CrossRef] [PubMed]

23. Stanton, R.; To, Q.G.; Khalesi, S.; Williams, S.L.; Alley, S.J.; Thwaite, T.L.; Fenning, A.S.; Vandelanotte, C. Depression, Anxiety and Stress during COVID-19: Associations with Changes in Physical Activity, Sleep, Tobacco and Alcohol Use in Australian Adults. Int. J. Environ. Res. Public Health 2020, 17, 4065. [CrossRef] [PubMed]

24. AlMughamis, N.; AlAsfour, S.; Mehmood, S. Poor eating habits and predictors of weight gain during the COVID-19 quarantine measures in Kuwait: A cross sectional study. F1000Research 2020, 9, 914. [CrossRef]

25. Salman, A.; Sigodo, K.O.; Al-Ghadban, F.; Al-Lahou, B.; Alnashmi, M.; Hermassi, S.; Chun, S. Effects of COVID-19 Lockdown on Physical Activity and Dietary Behaviors in Kuwait: A Cross-Sectional Study. Nutrients. 2021, 13, 2252. [CrossRef] 
26. Jukic, I.; Calleja-González, J.; Cos, F.; Cuzzolin, F.; Olmo, J.; Terrados, N.; Njaradi, N.; Sassi, R.; Requena, B.; Milanovic, L.; et al. Strategies and Solutions for Team Sports Athletes in Isolation due to COVID-19. Sports 2020, 8, 56. [CrossRef]

27. Di Fronso, S.; Costa, S.; Montesano, C.; Di Gruttola, F.; Ciofi, E.G.; Morgilli, L.; Robazza, C.; Bertollo, M. The effects of COVID-19 pandemic on perceived stress and psychobiosocial states in Italian athletes. Int. J. Sport Exerc. Psychol. 2020, 1-13. [CrossRef]

28. Lorenzo Calvo, J.; Granado-Peinado, M.; de la Rubia, A.; Muriarte, D.; Lorenzo, A.; Mon-López, D. Psychological States and Training Habits during the COVID-19 Pandemic Lockdown in Spanish Basketball Athletes. Int. J. Environ. Res. Public Health 2021, 18, 9025. [CrossRef]

29. Craig, C.L.; Marshall, A.L.; Sjöström, M.; Bauman, A.E.; Booth, M.L.; Ainsworth, B.E.; Pratt, M.; Ekelund, U.; Yngve, A.; Sallis, J.F.; et al. International Physical Activity Questionnaire: 12-Contry Reliability and Validity. Med. Sci. Sports Exerc. 2003, 35, 1381-1395. [CrossRef]

30. Lee, P.H.; Macfarlane, D.J.; Lam, T.H.; Stewart, S.M. Validity of the international physical activity questionnaire short from (PAQ-SF): A systematic review. Int. J. Behav. Nutr. Phys. Act. 2011, 8, 115. [CrossRef]

31. Ainsworth, B.E.; Haskell, W.L.; Whitt, M.C.; Irwin, M.L.; Swartz, A.M.; Strath, S.J.; O’Brien, W.L.; Bassett, D.R.; Schmitz, K.H.; Emplaincourt, P.O.; et al. Compendium of physical activities: An update of activity codes and MET intensities. Med. Sci. Sports Exerc. 2000, 32, S498-S504. [CrossRef]

32. Hermassi, S.; Bouhafs, E.G.; Bragazzi, N.L.; Ichimura, S.; Alsharji, K.E.; Hayes, L.D.; Schwesig, R. Effects of Home Confinement on the Intensity of Physical Activity during the COVID-19 Outbreak in Team Handball According to Country, Gender, Competition Level, and Playing Position: A Worldwide Study. Int. J. Environ. Res. Public Health. 2021, 18, 4050. [CrossRef]

33. Whitley, E.; Ball, J. Statistics Review 4: Sample Size Calculations. Crit. Care 2002, 6, 335-341. [CrossRef]

34. Ammar, A.; Chtourou, H.; Boukhris, O.; Trabelsi, K.; Masmoudi, L.; Brach, M.; Bouaziz, B.; Bentlage, E.; How, D.; Ahmed, M.; et al. COVID-19 Home Confinement Negatively Impacts Social Participation and Life Satisfaction: A Worldwide Multicenter Study. Int. J. Environ. Res. Public Health 2020, 17, 6237. [CrossRef]

35. Zhang, Y.; Ma, Z.F. Impact of the COVID-19 Pandemic on Mental Health and Quality of Life among Local Residents in Liaoning Province, China: A Cross-Sectional Study. Int. J. Environ. Res. Public Health 2020, 17, 2381. [CrossRef]

36. Hermassi, S.; Sellami, M.; Salman, A.; Al-Mohannadi, A.S.; Bouhafs, E.G.; Hayes, L.D.; Schwesig, R. Effects of COVID-19 Lockdown on Physical Activity, Sedentary Behavior, and Satisfaction with Life in Qatar: A Preliminary Study. Int. J. Environ. Res. Public Health 2021, 18, 3093. [CrossRef]

37. Diener, E.; Emmons, R.A.; Larsen, R.J.; Griffin, S. The Satisfaction with Life Scale. J. Personal. Assess. 1985, 49, 71-75. [CrossRef]

38. Kasteenpohja, T.; Marttunen, M.; Aalto-Setälä, T.; Perälä, J.; Saarni, S.I.; Suvisaari, J. Outcome of depressive and anxiety disorders among young adults: Results from the longitudinal Finnish health 2011 study. Nord. J. Psychiatry 2018, 72, 205-213. [CrossRef]

39. Bortz, J. Basic Principle of One-Factorial Analysis of Variance, in Statistics for Social Scientists; Springer: New York, NY, USA, 1999; pp. 237-249.

40. Hartmann, A.; Herzog, T.; Drinkmann, A. Psychotherapy of bulimia nervosa: What is effective? A meta-analysis. J. Psychosom. Res. 1992, 36, 159-167. [CrossRef]

41. Cohen, J. The effect size. In Statistical Power Analysis for the Behavioural Sciences; Taylor \& Francis: Abingdon, UK, $1988 ;$ pp. 77-83.

42. Richardson, J.T.E. Eta squared and partial eta squared as measures of effect size in educational research. Educ. Res. Rev. 2011, 6, 135-147. [CrossRef]

43. Hermassi, S.; Laudner, K.G.; Schwesig, R. The Effects of Circuit Strength Training on the Development of Physical Fitness and Performance-Related Variables in Handball Players. J. Hum. Kinet. 2020, 71, 191-203. [CrossRef]

44. Hermassi, S.; Chelly, M.S.; Fieseler, G.; Bartels, T.; Schulze, S.; Delank, K.S.; Shephard, R.J.; Schwesig, R. Short-Term Effects of Combined High-Intensity Strength and Sprint Interval Training on Anthropometric Characteristics and Physical Performance of Elite Team Handball Players. Sportverletz Sportschaden 2017, 31, 231-239. [CrossRef] [PubMed]

45. Bragazzi, N.L.; Rouissi, M.; Hermassi, S.; Chamari, K. Resistance Training and Handball Players' Isokinetic, Isometric and Maximal Strength, Muscle Power and Throwing Ball Velocity: A Systematic Review and Meta-Analysis. Int. J. Environ. Res. Public Health 2020, 17, 2663. [CrossRef] [PubMed]

46. Skoufas, D.; Skoufa, E.; Christodoulidis, T.; Papadopoulou, S.; Patikas, D.; Zaggelidis, G. The effect of arm and forearm loading on the throwing velocity of novice handball players: Influences during training and detraining. Phys. Train. 2008, 11, 1-12.

47. Fikenzer, S.; Fikenzer, K.; Laufs, U.; Falz, R.; Pietrek, K.; Hepp, P. Impact of COVID-19 lockdown on endurance capacity of elite handball players. J. Sports Med. Phys. Fit. 2020. online ahead of print. [CrossRef]

48. Ammar, A.; Mueller, P.; Trabelsi, K.; Chtourou, H.; Boukhris, O.; Masmoudi, L.; Bouaziz, B.; Brach, M.; Schmicker, M.; Bentlage, E.; et al. Psychological consequences of COVID-19 home confinement: The ECLB-COVID19 multicenter study. PLoS ONE 2020, 15, e0240204. [CrossRef]

49. Ammar, A.; Trabelsi, K.; Brach, M.; Chtourou, H.; Boukhris, O.; Masmoudi, L.; Bouaziz, B.; Bentlage, E.; How, D.; Ahmed, M.; et al. Effects of home confinement on mental health and lifestyle behaviours during the COVID-19 outbreak: Insight from the ECLB-COVID19 multicenter study. Biol. Sport 2020, 38, 37-44. [CrossRef]

50. Moreno-Pérez, V.; Del Coso, J.; Romero-Rodríguez, D.; Marcé-Hernández, L.; Peñaranda, M.; Madruga-Parera, M. Effects of home confinement due to COVID-19 pandemic on eccentric hamstring muscle strength in football players. Scand. J. Med. Sci. Sports 2020, 30, 2010-2012. [CrossRef] 
51. Lesser, I.A.; Nienhuis, C.P. The Impact of COVID-19 on Physical Activity Behavior and Well-Being of Canadians. Int. J. Environ. Res. Public Health 2020, 17, 3899. [CrossRef]

52. León-Zarceño, E.; Moreno-Tenas, A.; Boix Vilella, S.; García-Naveira, A.; Serrano-Rosa, M.A. Habits and psychological factors associated with changes in physical activity due to COVID-19 confinement. Front. Psychol. 2021, 12, 4. [CrossRef]

53. Ammar, A.; Mueller, P.; Trabelsi, K.; Chtourou, H.; Boukhris, O.; Masmoudi, L. Emotional consequences of COVID-19 home confinement: The ECLB-COVID19 multicenter study. medRxiv 2020. Preprint. [CrossRef]

54. Reardon, C.L.; Bindra, A.; Blauwet, C.; Budgett, R.; Campriani, N.; Currie, A. Mental health management of elite athletes during COVID-19: A narrative review and recommendations. Br. J. Sports Med. 2020. online ahead of print. [CrossRef]

55. Smith, B.M.; Twohy, A.J.; Smith, G.S. Psychological inflexibility and intolerance of uncertainty moderate the relationship between social isolation and mental health outcomes during COVID-19. J. Contextual. Behav. Sci. 2020, 18, 162-174. [CrossRef]

56. Sallis, R.; Young, D.R.; Tartof, S.Y.; Sallis, J.F.; Sall, J.; Li, Q.; Smith, G.N.; Cohen, D.A. Physical inactivity is associated with a higher risk for severe COVID-19 outcomes: A study in 48,440 adult patients. Br. J. Sports Med. 2021, 55, 1099-1105. [CrossRef]

57. Toresdahl, B.G.; Asif, I.M. Coronavirus disease 2019 (COVID-19): Considerations for the competitive athlete. Sports Health 2020, 12, 221-224. [CrossRef]

58. Herrera-Valenzuela, T.; Valdés-Badilla, P.; Franchini, E. High-intensity interval training recommendations for combat sports athletes during the COVID-19 pandemic. RAMA 2020, 15, 1-3. [CrossRef] 